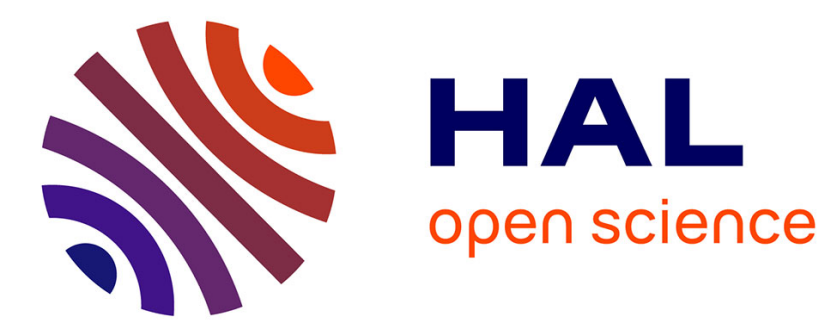

\title{
Evaluating Collaboration and Governance in SME Clusters
}

Teresa Taurino

\section{To cite this version:}

Teresa Taurino. Evaluating Collaboration and Governance in SME Clusters. 16th Working Conference on Virtual Enterprises (PROVE), Oct 2015, Albi, France. pp.388-397, 10.1007/978-3-319-241418_35. hal-01437907

\section{HAL Id: hal-01437907 https://hal.inria.fr/hal-01437907}

Submitted on 17 Jan 2017

HAL is a multi-disciplinary open access archive for the deposit and dissemination of scientific research documents, whether they are published or not. The documents may come from teaching and research institutions in France or abroad, or from public or private research centers.
L'archive ouverte pluridisciplinaire HAL, est destinée au dépôt et à la diffusion de documents scientifiques de niveau recherche, publiés ou non, émanant des établissements d'enseignement et de recherche français ou étrangers, des laboratoires publics ou privés.

\section{(c)(1)}

Distributed under a Creative Commons Attribution| 4.0 International License 


\title{
Evaluating Collaboration and Governance in SME Clusters
}

\author{
Teresa Taurino' \\ Politecnico di Torino, DIGEP - Departmento of Management and Industrial Engineering. \\ Corso Duca degli Abruzzi, 24, 10129 Torino, Italy \\ teresa.taurino@polito.it
}

\begin{abstract}
The need of collaboration among SMEs and improving governance has been perceived by the European Commission and by individual countries that promote since some years new organizational transformations of industrialservice systems into sustainable networks. The proposed paper is intended to address: How a manager of an individual SME, aiming to join an existing cluster, can evaluate a cluster that could be a "collaborative environment" for his small business; which main characteristics of the cluster governance have to be analyzed; which network structures appear to be preferable with a mutual profit? To help the manager to answers to these questions, the proposed work establishes a Cluster Reference Framework (CRF) structured in three dimensions: (i) the types of SME clusters; (ii) the types of governance (management) committee; (iii) the different ways of creating a network of small businesses, depending on whether or not there is a promoter or an independent will.
\end{abstract}

Keywords: SME clusters, graph representation, collaboration, management committee.

\section{Introduction}

The need for strengthening cooperation among SMEs and improving networking has been perceived of interest by the European Commission [1] and by individual countries [2] that promote, since some years, new organizational transformations of industrial-service systems into sustainable networks.

The industrial network systems, in Europe, rise from different needs and with different characteristics [3, 4]. The Italian industrial districts and the UK clusters of SMEs have in common the characteristic to be agglomerations of SMEs from the same geographic area. The development of the network [5] can be determined by the possibility to easily supply raw materials, the presence of a big local market and the availability of a high level of expertise in a specific manufactured sector. In France, it is common to find "Pole of Competitiveness" as well as the "Scientific Parks" in Greece. This kind of networks rise thanks to national or regional governments 
incentives to develop a common project. In other countries, like Germany, the SME networks rise around a leading firms that have the characteristics to pull all the SMEs in the market.

The promotion of the clustering or networking of companies can be reached according different routes:

- stimulated by local training centers that helps the enterprises to create an organic product service system in order to meet better the demand of the labor market;

- driven by the need to share the resources and to collaborate in order to face the adverse market environments;

- the local public administration, or agencies/associations for industrial and commercial development asks SMEs to strengthen cooperation, often during times of crisis.

"A product service-system" is composed by products, services, resources, buildings and personnel that continuously work to be more competitive, to satisfy the needs of the market by paying attention to the environmental impact with less effort with than a traditional business models" [6].

Despite the pressure towards cooperation, many SME managers have maintained their individualistic position: this has reflected in many dramatic crises and closures of small businesses, especially in recent years $[7,8]$.

Consequently the problem discussed in the proposed paper is intended to address the following questions: How does a manager of an SME assess whether an existing cluster could be a "friendly environment" for his small business? What organizational characteristics of the cluster have to be analyzed? Which network structures appear to be preferable such as the SME would fit into the existing network with mutual profit? In order for the manager to look for answers to these questions, the proposed work establishes a Cluster Reference Framework (CRF) structured in three dimensions:

- the types of SME clusters, modeled in terms of standard networked graphs, such to allow an easy view of the networked links connecting SMEs;

- the types of management committee, that should assure cooperation among the SMEs together;

- the different ways of creating a network of small businesses, depending on whether or not there is a promoter or an independent will.

Even considering only these three dimensions, they offer criteria for analysis and evaluation of a SME cluster ("marginal analysis"). However, considering them in pairs, other points of view for the analysis are obtained:

a) taking into account the pair <network type; type of committee> one can get information about organizational transformation applicable to the network;

b) from the analysis of the pair <network type; procedures for setting up the network $>$ design tips arise;

c) in addition, an analysis of the pair <type of committee; how to build > can give information on sustainability of the network.

The paper will motivate in detail the CRF, and show its practical utilization by a SME manager. To this aim, the paper is organized as follows. The introduction of a model of a SME cluster, by making evidence to the two components above mentioned, namely types of networks connecting the partner SMEs together, and types of cluster management is in Section 2. Depending on these two components, a classification of 
the different SME clusters can be standardized. Section 3 will illustrate a threedimensional framework, namely the mentioned Cluster Reference Framework - CRF, where the types of networks, the types of management organizations and the different ways to create a network of small enterprises will be respectively referred to each dimension. The potential practical utilization of the proposed framework will be discussed by showing how the presented framework can support a specific analysis of a SME manager. Section 3 will also illustrated a preliminary application of the CRF, by analyzing the three types of dimensions for a number of SME clusters, based on data collected during the European project CODESNET and stored in the CODESNET archive. The European project CODESNET (COllaborative DEmand and Supply NETwork) aimed to create a virtual environment to promote the development of SME network. During the project, a huge number of data and information concerning more than 100 SME networks have been collected. CODESNET has relied on the contribution from both enterprises and academia partners since this synergy is considered a strong point in order to guarantee stability in a network organization.

\section{Modeling a SME Cluster}

Three important aspects must be taken into account in the modeling of SME networks $[9,10]$ :

- the management of the network in terms of functionalities that can assure efficiency, effectiveness and economy in all the SMEs belonging to the network;

- the structure of the connections among the SMEs, that means the type of their relationships;

- the reasons at the origin of the aggregation of multiple companies in a common network.

\subsection{Main Functions and Management Organization of a SME Cluster}

The management organization of a SME cluster can be represented by a "functional scheme" that represents the main functionalities and that shows how the committee of the cluster can receive contributions from the partners of the cluster, can generate products and financial strategies and can translate strategies into action plans able to satisfy customers orders by using the cluster structure to produce. In the next Fig.1, the functional scheme is presented: " $\mathrm{A}$ " denotes the operations control loop; " $\mathrm{B}$ ", the performance evaluation loop; "C", the finance management loop; "D", the partners' interactions management loop.

In practice, the real application of all these management functions depends on the type of cluster committee. Consequently, it can be stated that the presence of a particular type of committee characterizes a SME network defining the robustness and 
the possibility of a real future development. With reference to the cluster analysed in the project CODESNET, you can recognize the following types of the Management Committee:

- Industrial management committee, i.e. a committee composed by the top managers of the most important enterprises included in the cluster: among the managers, a coordinator is usually nominated. This is the case of small and mid-size enterprises operating in the manufacturing sector, as automotive, aerospace, electronic ones; in this organization, all the management functions of Fig. 1 are applied.

- Administration management committee, i.e. a committee composed by administrative directors or, more generally, by administrative staff, of some companies in the cluster, with the task of monitoring costs and revenues on behalf of individual companies, and of reporting to external funders (function $\mathrm{C}$ in Fig. 1). This can be the case of clusters having a leading enterprise, whose aim is to monitor financial flows without completely removing autonomy to other SME of the cluster.

- Marketing-oriented committee, i.e. a committee made up of directors of marketing for some companies, with the task of managing specific marketing initiatives, such as exhibitions, promotional campaigns or advertising (function A in Fig. 1). This is the case of SME clusters of the jewelry sector.

- Political committee, i.e. a committee composed by representatives of the municipalities where the SMEs belonging to the cluster are located; this is the case of some clusters operating in the agro-food sector, as in production of wine. A political committee is a committee that can implement at most promotional functions, but does not have operational duties.

- No committee, i.e. a form of weak interaction, partly marketing - oriented and partly characterized by a political and social nature, with the sole purpose to create a market to the SMEs.

\subsection{Models of the Network of SMEs}

A network of SME can be easily modelled by a graph $G=(V, E)$, where $V$ is the set of vertices and $E$ is the set of edges or arcs. Each vertex corresponds to a SME of the cluster and the edges correspond to the links among the SMEs.

The SME-to-SME connections can have different characteristics:

1. can represent the connection between a client and a supplier and in this case the links is mainly characterized by the flow of parts from a SME to another;

2. can be the exchange of information and from one SME to another into a cluster information system;

3. can be the transfer of orders either between SMEs or between a SME and a common centre, as part of a cluster management organization. 


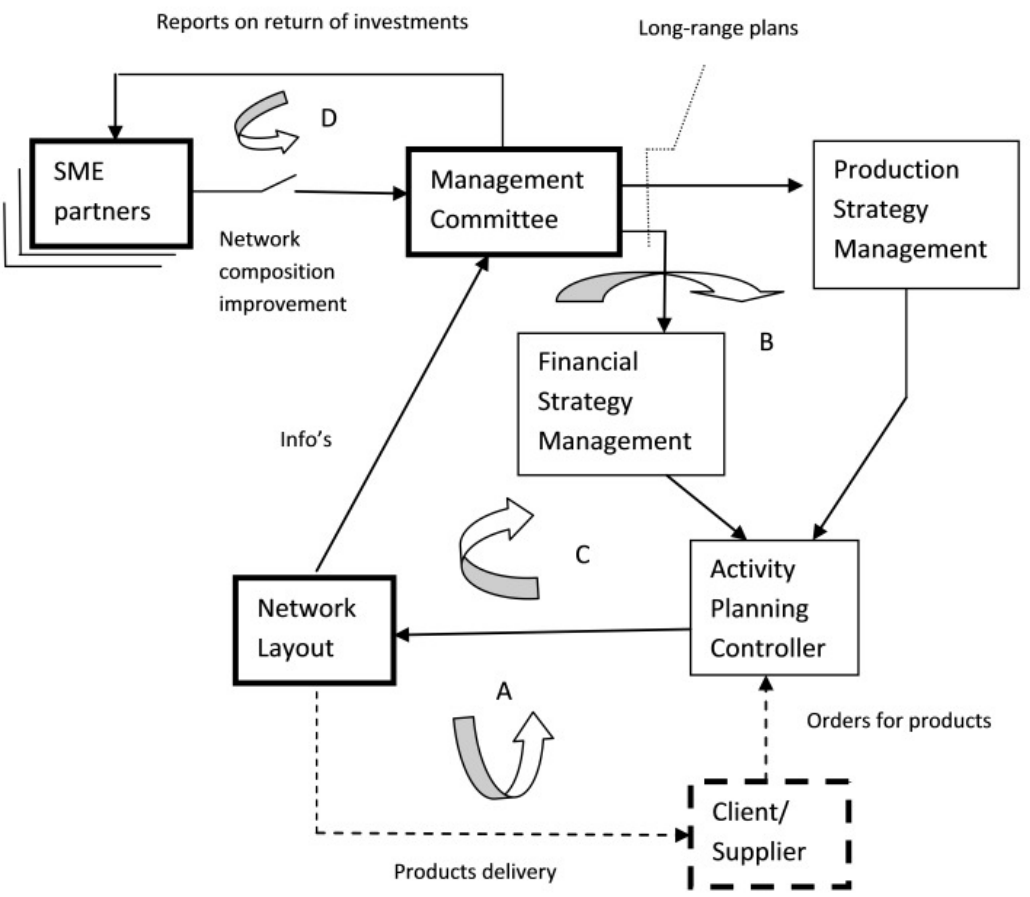

Fig. 1. Schematic model of an industrial SME network.

In this analysis of manufacturing SME networks, we will refer to a graph representing the exchange of material among SME so the links among SMEs are characterized by a physical exchange of parts or materials.

Depending on the type of production flows connections of SMEs, a classification of the network layout has been defined, by identifying four network graphs illustrated in the next Fig. 2. The boundaries of the network are represented by a rectangle; the small and medium enterprises are represented by numbered circles and the edges are indicated with oriented arc. S and D represent, respectively, the Source and the Destination node. In Fig. 2 a Job Shop (JS) is represented [11, 12]. This network's configuration is characterized by a set of SMEs able to provide and receive material from the SMEs they are linked to and the presence of circle is allowed. In this first type of configuration, the growth of the network is determined basically by the geographical proximity and the similarity in the production. The "supply chain" or, more generally, "multi-stage supply chain" [13] can be recognized as a second type of SMEs aggregation. In this kind of network, the relationships among the enterprises are of client/supplier along the production chain that ends with an important leading enterprise whose brand is known all over the world. The structure, in terms of graph, of a Multi-stage Supply Chain (SC) is represented in Fig 2b: arrows represent the 
connections between two SME typically characterized by an exchange of material or components. In this network configuration cycles are not allowed. Fig. 2c gives a simplified illustration of the Hub-and-Spoke (HS) type. The main characteristic of the Hub-and-Spoke network is the presence of a leading firms to whom almost all the other SMEs are connected. It is possible to recognize this type of network since it does not allow cycles and the node corresponding to the leading firm has a high number of entering edges with respect to the other nodes. The last type of aggregation proposed has less ruled interactions that permit to recognize the aggregation. This type of networks is mainly exploited by high-tech production and/or service supply where the nature of such aggregation is mainly oriented to R\&D. This configuration is named Scientific Park (SP) [14, 15] and, in terms of graph representation, the nodes can be considered as inserted in a pre-existing with very flexible and more informal connections. To differentiate these potential connections from the classical ones, we represent them as switches on the graph edges. An example of the Scientific Park network is shown in Fig. 2d.
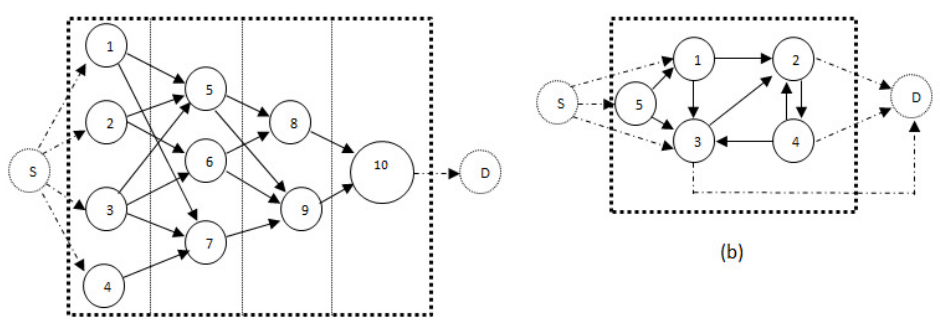

(b)

(a)

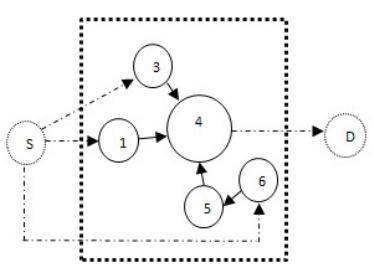

(c)

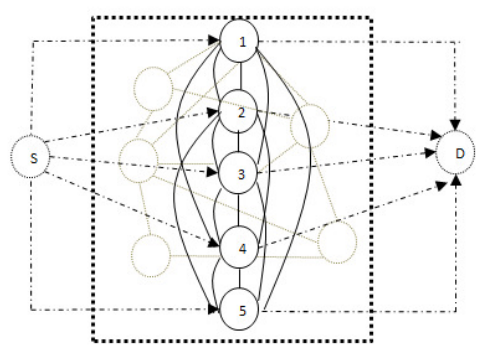

(d)

Fig. 2. Graph representation of the four network types.

The typical feature of a Scientific Park is that each node is connected directly with the source and the destination nodes due to the pre-existing network. Furthermore, all possible edges between nodes can be activated or interrupted at any time. The exchanges between such companies do not concern materials or components but rather exchanges of information (knowledge, data, models, ideas) and services, thanks to the underlying network of partners specialized in ICT (Information and Communication Technology) and support to the innovative activities. 


\subsection{Models of a SME Cluster Dimension Dynamics}

The differences in the creation and in the structure of the enterprise clusters give rise to different types of SME networks, as it has been presented in $[15,16]$ where an overview of clusters in some European countries has been illustrated. In some countries, like Italy, Germany and UK, the enterprises networks have raised in an autonomous way, pushed either by the companies themselves, or by industry organizations. In countries like France and Greece, the national or local governments have promoted investment programs to push the aggregation of SME into networks. The free aggregation of SMEs can occur either in a territory with no boundaries (if there are no specific requirements from logistics needs of the production) or in a limited small geographical area, due to the necessity of a strict collaboration and a strong sharing of resources and information or the exchange of parts or materials. The creation of a collaborative network can be autonomously induced by the strategic vision of the managers of the SMEs in order to plan and manage their production activity. This type of aggregation is named Autonomous or Marshallian and two particular models of SMEs networks prevail: Supply Chain (SC) and Job-Shops (JS). In the JS network, since the circles are allowed, each SME can both provide and receive products/services from the others. The SC network is characterized by the presence of a chain composed by two or more stages with a number of parallel SMEs which provide products/services to the SMEs in the following stage. When firms of different size and different strength in the final product market agree to activate together connections depending on one (or few) leading SME we can speak of Huband-Spoke networks. In the HS networks one or two leading firms push to create a network of suppliers in order to drag the production and increase their performance and their position on the local and external market. The aggregation of the Scientific Parks is driven by a public body through a collaborative project founded by national, international or private bodies. The SPs are characterized by high skills, high technologies, and high innovation, requiring a high sharing of knowledge, resources, information, and skills. The aggregation approach cannot be based on autonomy of SMEs: large investments are required as well as an accurate selection of both SMEs and the personnel of high qualification to be employed.

\section{The Cluster Reference Framework - CRF}

The three main aspects of a SME cluster model, namely SME network type, management organization, and cluster creation, define three dimensions of a frame as in Fig. 3. This frame can be seen as a three-dimensional matrix, each internal box is associated to a triplet: <network type; type of Management body; network's agreement $>$. Said triplet specifies a SME cluster type. In each box, the names of some SME clusters (among the ones stored in the CODESNET archive) can be located: then, each box offers to a SME manager a set of preliminary information for evaluating if joining the considered network type could be of some interest for his/her SME. The real utilization of the schematic model of Fig. 3 can be realized by 
considering some Italian industrial districts. In the next Table 1 a set of data of Industrial networks belonging to the CODESNET archive are given.

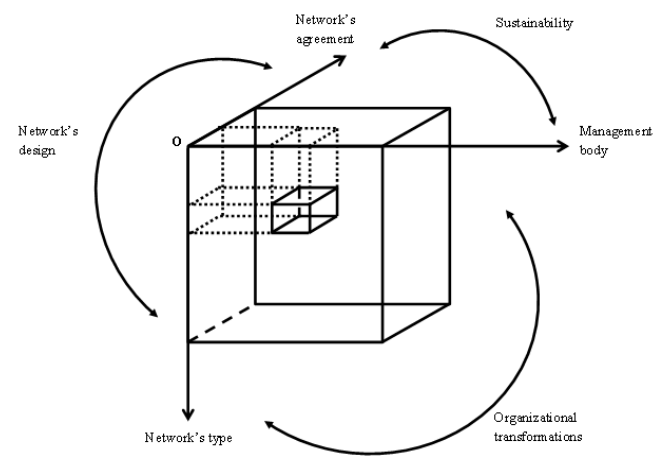

Fig. 3. Schematic model of CRF.

\subsection{Example of Application}

An example of specific analysis has been done by referring to the manufacturing sector, with attention to districts producing shoes. The manager of a SME of this same sector, aiming to join a district, has at disposal the "archive" illustrated in Fig. 3. He will use the archive boxes tagged with the word "product = shoes", thus obtaining the following Table 1.

Table 1. Selected Industrial District from the CODESNET "archive".

\begin{tabular}{llll}
\hline District Name & Network Type & Management body & Network creation \\
\hline Fermo & HS & None- existence of leading firms & Free aggregation \\
Vigevano & SC & None- No leading firms & Free aggregation \\
Lucca & SC & None- No leading firms & Free aggregation \\
Verona & SC & Marketing-oriented committee & Free aggregation \\
San Mauro Pascoli & SC & Marketing-oriented committee & Free aggregation \\
\hline
\end{tabular}

The selected boxes, however, are referred to different triplets, and then the manager receives the following information:

a) Fermo's District:

- $\quad$ Network type = Hub and Spoke;

- $\quad$ Management body = none (existence of leading firms);

- Network creation = free aggregation.

b) Vigevano's District and Lucca's District:

- $\quad$ Network type = Supply Chain;

- $\quad$ Management body = none (no leading firms in the chain stages);

- $\quad$ Network creation $=$ free aggregation 
c) Verona's District and San Mauro Pascoli's District:

- $\quad$ Network type = Supply Chain;

- $\quad$ Management body =Marketing-oriented committee;

- Network creation = free aggregation

In summary, manager asking for joining suggestions can get:

- A common information: all districts aim to accept new partners, being born from "free aggregation".

- Specific information: make a choice between a cluster where a leader will plan the future and a cluster where, at most, common marketing strategies could be plan together. Depending on the manager's desire to maintain large autonomy and to be supported, the "archive" of Fig. 3 can provide immediate, even if preliminary, suggestions.

\section{Conclusions}

The analysis of a number of industrial districts, collected during the development of the EU CODESNET project and his evolution in national research programs, gave rise to a complete model of an industrial SME cluster, with three main complementary aspects (and model components): SME network cluster, management committee, and cluster creation dynamics. A graphical three dimensional representation of the cluster model has been presented. This same representation has to be interpreted as an "archive" of cluster data/information. This archive is useful tool for a manager who aims to join a cluster, but wants to take its decision based on a sufficient view of the cluster main characteristics.

In summary, manager asking for joining a district can get the following suggestions:

- As general information: all districts aim to accept new partners, if they have been born from "free aggregation";

- As specific information: make a choice between a cluster where a leader will plan the future and a cluster where, at most, common marketing strategies could be planned together.

The two above suggestions (that could be improved by taking into account of the district management body as well as of the district dimensions, as number of components and number of connections among them) can help the manager to take a decision, even if preliminary but sufficient to give him main lines to contact the district representative and negotiate for a potential joining agreement.

\section{References}

1. Villa A. and Bruno G., Promoting SME cooperative aggregations: main criteria and contractual models, Int. J. Production Research, vol. 51, N. 23-24, December 1-15, 2013. 
2. Bruno G., Villa A., An ontology-based model for SME network contracts, Lecture Notes in Computer Science, Vol. 7567, 85-92, 2012.

3. Villa A., Antonelli D., Strengthening SME network governance, in A. Villa and D. Antonelli (Eds.), A Road Map to the Development of European SME Networks, SpringerVerlag, London, pp. 61-69, 2009.

4. Antonelli D., Taurino T., Identifying and exploiting the collaboration factors inside SMEs networks, INTERNATIONAL JOURNAL OF NETWORKING AND VIRTUAL ORGANISATIONS, 2011, vol. 9, p.382-402, ISSN: 1470-9503.

5. Taurino T., Antonelli D., Analysis of Potential Collaborations in SME Networks. In: INCOM '09 - 13th IFAC Symposium on Information Control Problems in Manufacturing, 2009, Moscow, Russia, 3-5 June 2009.

6. Goedkoop, M., van Haler, C., te Riele, H., and Rommers, P. Product Service-Systems, ecological and economic basics. Report for Dutch Ministries of Environment (VROM) and Economic Affairs (EZ), 1999.

7. Tomlinson P.R., Fai F.M., The nature of SME co-operation and innovation: A multi-scalar and multi-dimensional analysis, International Journal of Production Economics, 2013, Vol. 141, 316-326.

8. Antonelli D., Caroleo B, Taurino T., Pattern Recognition from Data Collection on Industry Networks. SYSTEMS SCIENCE, 2007, vol. 33, pp. 81-90, ISSN: 0137-1223.

9. Taurino T., Antonelli D., An insight into Innovation Patterns of Industrial Districts. In: 6th CIRP International Conference on Intelligent Computation in Manufacturing Innovative and Cognitive Production Technology and Systems, 2008, Naples, Italy, 23-25 July 2008.

10. Markusen A., Sticky Places in Slippery Space: A Typology of Industrial Districts. Economic Geography, Volume 72, Issue 3 (Jul., 1996), 293-313.

11. Coe N.M., A Hybrid Agglomeration? The Development of a Satellite-Marshallian Industrial District in Vancouver's Film Industry, Urban Studies, 2008, Vol. 38, No.10, 17531775.

12. Bogataj M., Grubbstrom R.W., Bogataj L., Efficient location of industrial activity cells in a global supply chain, International Journal of Production Economics, 2011, Vol. 133, Issue 1, 243-250.

13. Villa A., Taurino T., Ukovich W., Supporting collaboration in European Industrial Districts - The CODESNET approach, Journal of Intelligent Manufacturing, (25 February 2011), pp. 1-10, doi:10.1007/s10845-011-0516-6.

14. Boja C., Clusters Models, Factors and Characteristics, International Journal of Economic Practices and Theories, Vol 1, No.1, 2011, 34-43.

15. Villa A. and Taurino T., Cooperative agreements for SME network organization, in A. Villa (ed.), Managing Cooperation in Supply Newtwork Structures and Small or Medium-Sized Enterprises, Springer-Verlag, London, pp. 19-34, 2011.

16. Villa A. and Taurino T., SME networks and clusters: An approach to their performance evaluation, in A. Villa (ed.), Managing Cooperation in Supply Newtwork Structures and Small or Medium-Sized Enterprises, Springer-Verlag, London, pp. 65-88, 2011.

17. CODESNET: COllaborative DEmand and Supply NETwork, European Coordination Action, EU-funded project EU FP7. 